\title{
Supporting Information for Factors Governing Oxygen Vacancy Formation in Oxide Perovskites
}

Robert B. Wexler†, Gopalakrishnan Sai Gautam†, Ellen B. Stechel§ ${ }^{\S}$ and Emily A. Carter†,

†Department of Mechanical and Aerospace Engineering, Princeton University, Princeton, NJ 08544-5263, United States, \& ASU Lightworks and the School of Molecular Sciences, Arizona State University, Tempe, Arizona 85287-5402, United States, and $¥$ Office of the Chancellor and Department of Chemical and Biomolecular Engineering, University of California, Los Angeles, Los Angeles, CA 90095, United States

Table S1. Computational cost associated with $\mathrm{PBE}, \mathrm{PBE}+U=3.9,{ }^{1} \mathrm{SCAN}$, and $\mathrm{SCAN}+U=2.7^{2}$ self-consistentfield calculations for four "high quality" experimental crystal structures of $\mathrm{BaMnO}_{3}$. ICSD is the Inorganic Crystal Structure Database Collection Code and $t$ is time. Input parameters are the same as those in the main text.

\begin{tabular}{|c|c|c|c|c|c|c|c|c|c|c|c|c|}
\hline \multirow{2}{*}{$\begin{array}{c}\text { ICSD } \\
10250\end{array}$} & \multicolumn{2}{|c|}{ Space Group } & \multirow{2}{*}{$\begin{array}{c}\text { \# Atoms } \\
40\end{array}$} & \multirow{2}{*}{$\begin{array}{l}X C \\
\text { PBE }\end{array}$} & \multirow{2}{*}{$\frac{U}{0.0}$} & \multirow{2}{*}{$\frac{t(s)}{1077}$} & \multirow{2}{*}{$\begin{array}{c}\text { \# Steps } \\
21\end{array}$} & \multirow{2}{*}{$\frac{t_{s}=t / s t e p}{51}$} & \multirow{2}{*}{$\frac{\min (t)}{939}$} & \multirow{2}{*}{$\frac{t / \min (t)}{1.15}$} & \multirow{2}{*}{$\frac{\min \left(t_{s}\right)}{51}$} & \multirow{2}{*}{$\begin{array}{c}t_{s} / \min \left(t_{s}\right) \\
1.00\end{array}$} \\
\hline & $P 6_{3} / m m c$ & 194 & & & & & & & & & & \\
\hline 10250 & $\mathrm{PG}_{3} / \mathrm{mmc}$ & 194 & 40 & PBE & 3.9 & 939 & 18 & 52 & 939 & 1.00 & 51 & 1.02 \\
\hline 10250 & $\mathrm{PG}_{3} / \mathrm{mmc}$ & 194 & 40 & SCAN & 0.0 & 2402 & 22 & 109 & 939 & 2.56 & 51 & 2.13 \\
\hline 10250 & $P 6_{3} / m m c$ & 194 & 40 & SCAN & 2.7 & 1997 & 21 & 95 & 939 & 2.13 & 51 & 1.85 \\
\hline 66822 & $R \overline{3} m$ & 166 & 54 & PBE & 0.0 & 1290 & 19 & 68 & 1287 & 1.00 & 68 & 1.00 \\
\hline 66822 & $R \overline{3} m$ & 166 & 54 & PBE & 3.9 & 1287 & 19 & 68 & 1287 & 1.00 & 68 & 1.00 \\
\hline 66822 & $R \overline{3} m$ & 166 & 54 & SCAN & 0.0 & 2770 & 22 & 126 & 1287 & 2.15 & 68 & 1.86 \\
\hline 66822 & $R \overline{3} m$ & 166 & 54 & SCAN & 2.7 & 3024 & 21 & 144 & 1287 & 2.35 & 68 & 2.13 \\
\hline 89994 & $\mathrm{PG}_{3} / \mathrm{mmc}$ & 194 & 10 & PBE & 0.0 & 192 & 19 & 10 & 166 & 1.16 & 10 & 1.00 \\
\hline 89994 & $\mathrm{PG}_{3} / \mathrm{mmc}$ & 194 & 10 & PBE & 3.9 & 166 & 16 & 10 & 166 & 1.00 & 10 & 1.03 \\
\hline 89994 & $\mathrm{P}_{3} / \mathrm{mmc}$ & 194 & 10 & SCAN & 0.0 & 411 & 20 & 21 & 166 & 2.48 & 10 & 2.03 \\
\hline 89994 & $\mathrm{PG}_{3} / \mathrm{mmc}$ & 194 & 10 & SCAN & 2.7 & 333 & 15 & 22 & 166 & 2.01 & 10 & 2.20 \\
\hline 89995 & $\mathrm{P6}_{3} \mathrm{~cm}$ & 185 & 30 & PBE & 0.0 & 1189 & 22 & 54 & 764 & 1.56 & 45 & 1.20 \\
\hline 89995 & $\mathrm{PG}_{3} \mathrm{~cm}$ & 185 & 30 & PBE & 3.9 & 764 & 17 & 45 & 764 & 1.00 & 45 & 1.00 \\
\hline 89995 & $\mathrm{PG}_{3} \mathrm{~cm}$ & 185 & 30 & SCAN & 0.0 & 1612 & 18 & 90 & 764 & 2.11 & 45 & 1.99 \\
\hline 89995 & $\mathrm{PG}_{3} \mathrm{~cm}$ & 185 & 30 & SCAN & 2.7 & 1435 & 16 & 90 & 764 & 1.88 & 45 & 2.00 \\
\hline
\end{tabular}


(a) A-site

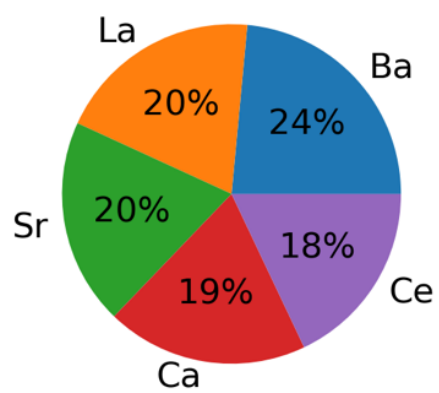

(b) B-site

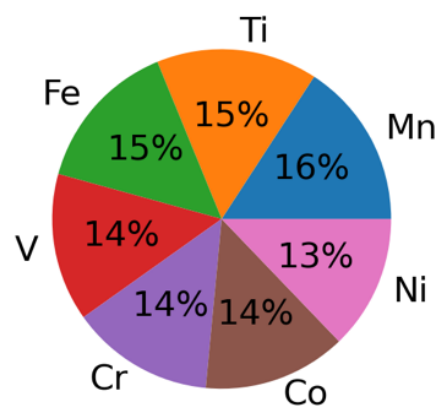

(c) Lattice system

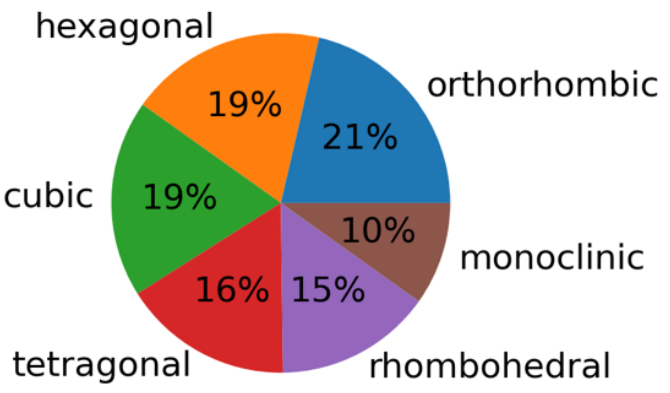

Figure S1. Distribution of $\mathrm{ABO}_{3}$ perovskite structures in the bulk by (a) A-site, (b) B-site, and (c) lattice system. We tabulated structures, total free energies, energies for $\sigma \rightarrow 0$ where $\sigma$ is the width of the Gaussian smearing, magnetizations, local charges and magnetic moments, and band gaps for pristine primitive cells and supercells in bulk.csv.

(a) A-site

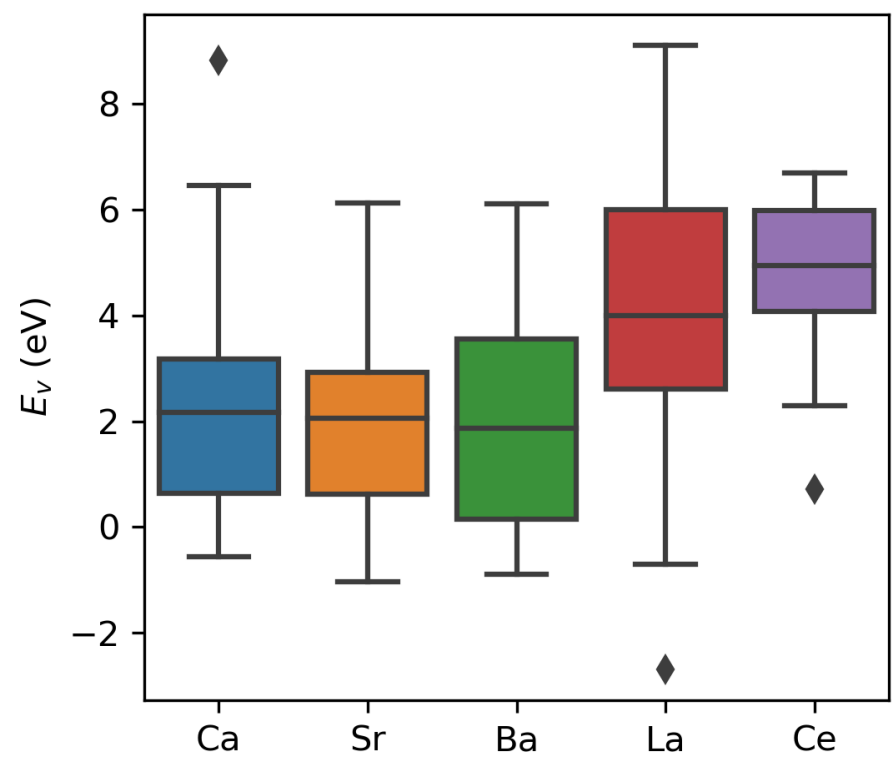

(b) B-site

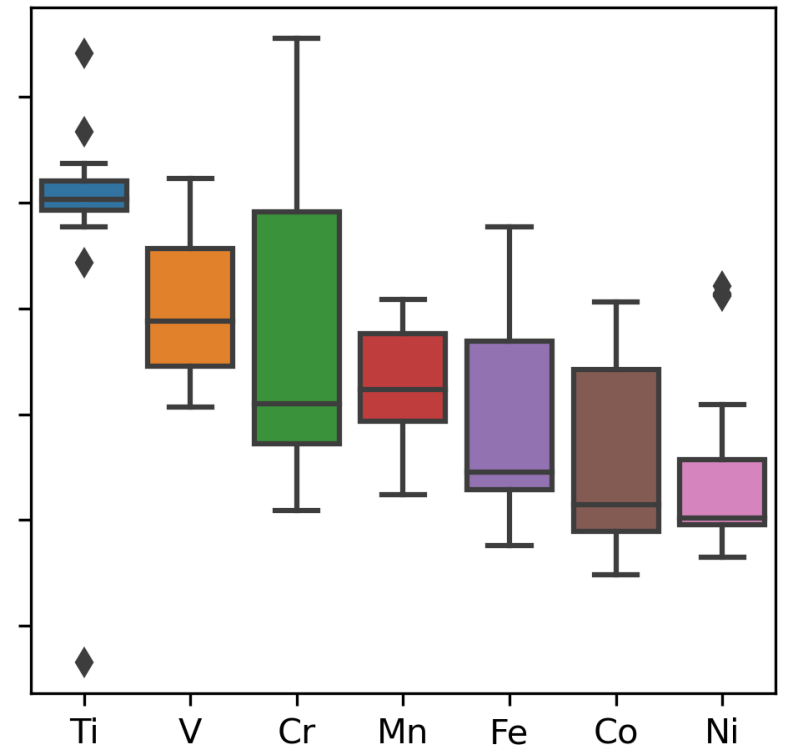

Figure S2. Distribution of neutral oxygen vacancy formation energies $\left(E_{v}\right)$ for $\mathrm{ABO}_{3}$ perovskite structures by (a) A-site and (b) B-site. The boxes show the quartiles of the data subsets while the whiskers show the rest of the distribution, except for points that are outside 1.5 IQR (diamonds) where IQR is the interquartile range. We tabulated structures, total free energies, energies for $\sigma \rightarrow 0$, magnetizations, local charges and magnetic moments, band gaps, and $E_{v}$ for defective supercells in defects.csv. 
(a) $\mathrm{LaCrO}_{3}(\mathrm{R} \overline{3} \mathrm{c})$

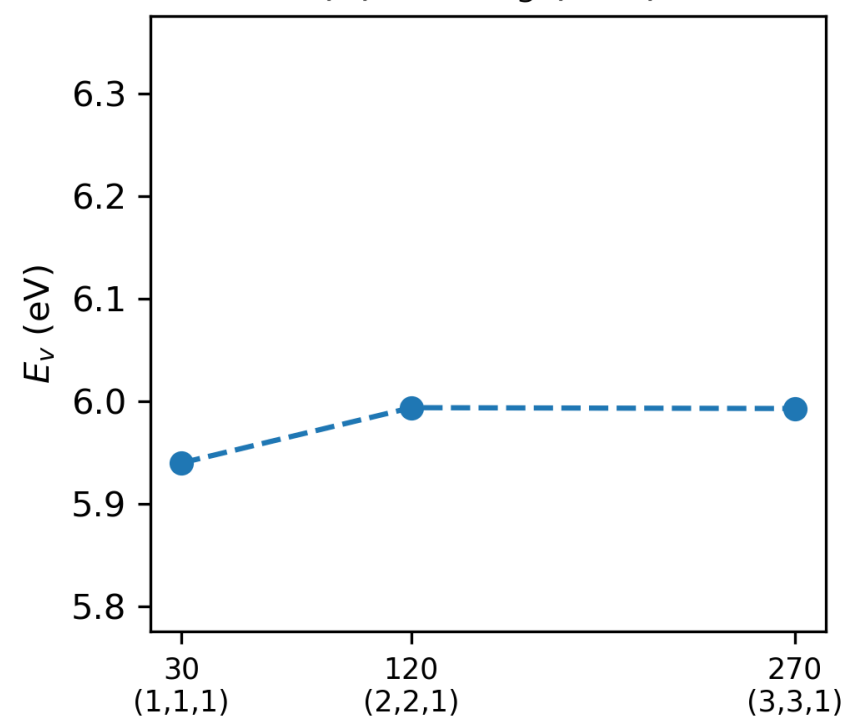

(c) $\mathrm{BaTiO}_{3}(\mathrm{Pm} \overline{3} \mathrm{~m})$

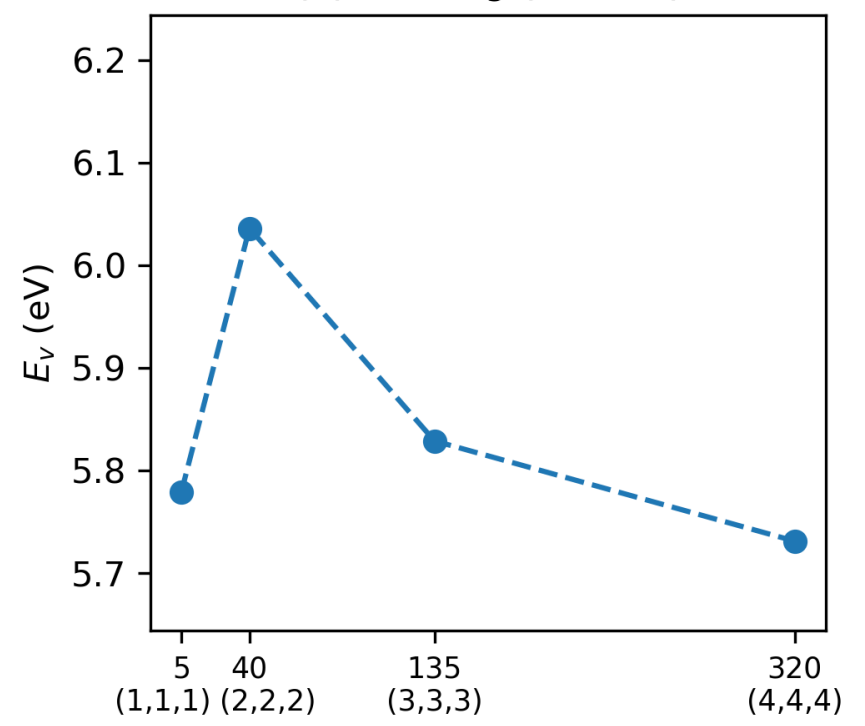

Number of atoms (supercell dimensions) (b) $\mathrm{CaTiO}_{3}$ (Pnma)

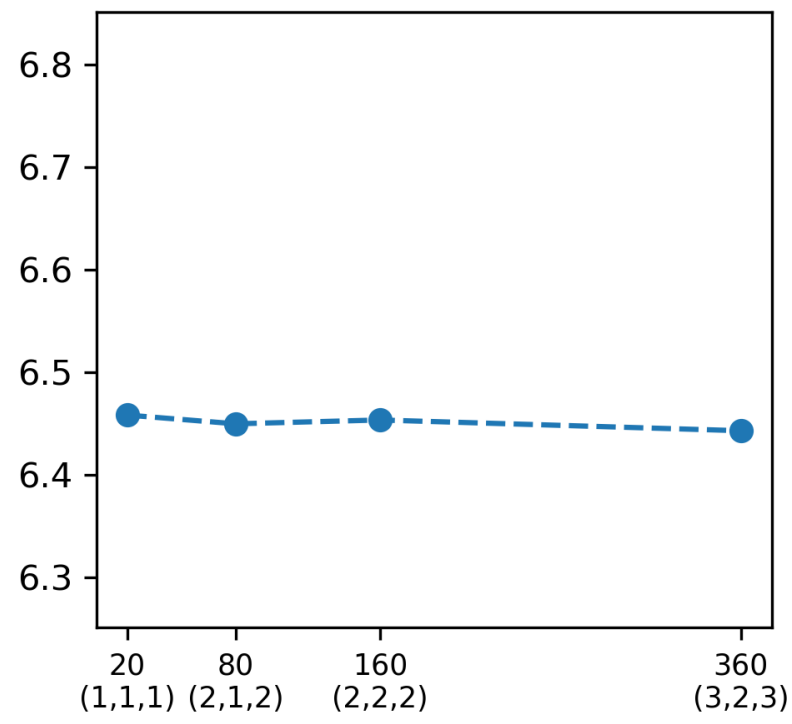

(d) $\mathrm{SrMnO}_{3}\left(\mathrm{PG}_{3} / \mathrm{mmc}\right)$

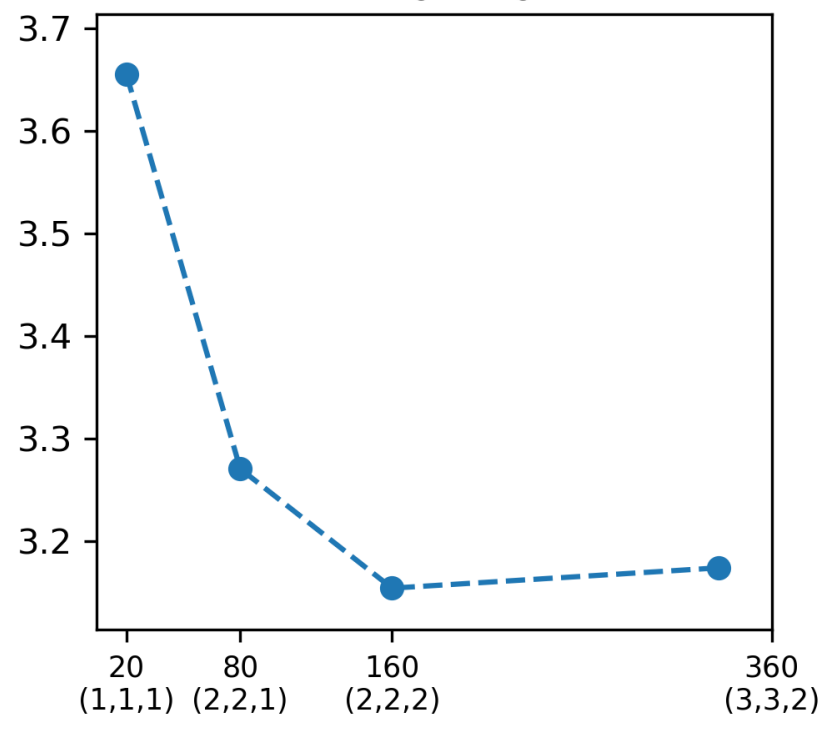

Number of atoms (supercell dimensions)

Figure S3. Convergence of $E_{v}$ in (a) $\mathrm{LaCrO}_{3}(R \overline{3} c)$, (b) $\mathrm{CaTiO}_{3}(P n m a)$, (c) $\mathrm{BaTiO}_{3}(P m \overline{3} m)$, and (d) $\mathrm{SrMnO}_{3}$ $\left(\mathrm{P}_{3} / \mathrm{mmc}\right)$. We did not explicitly perform convergence tests for tetragonal $(P 4 \mathrm{~mm})$ and monoclinic $\left(P 2_{1} / b\right)$ structures since they share similar lattice parameters with cubic $(P m \overline{3} m)$ and orthorhombic (Pnma) structures, respectively. 
(a) A-site

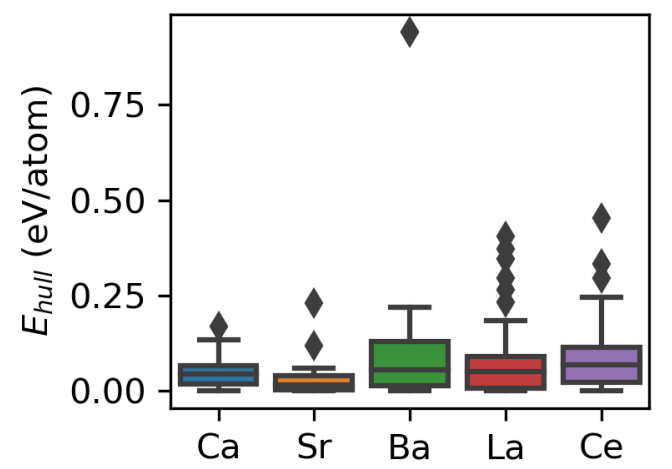

(b) B-site

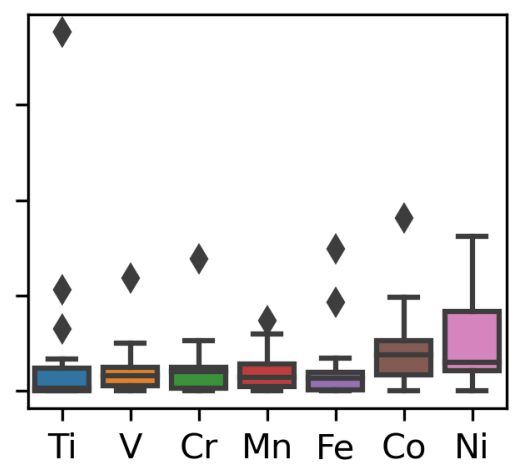

(c) Lattice system

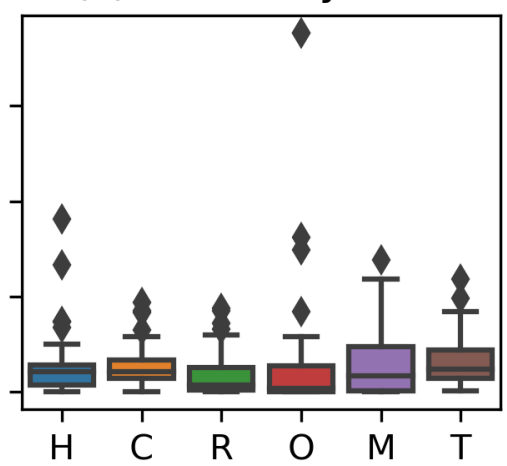

Figure S4. Distribution of energies above the convex hull ( $\left.E_{\text {hull }}\right)$ for $\mathrm{ABO}_{3}$ perovskite structures by (a) Asite, (b) B-site, and (c) lattice system. The boxes show the quartiles of the data subsets while the whiskers show the rest of the distribution, except for points that are outside 1.5×IQR (diamonds) where IQR is the interquartile range.

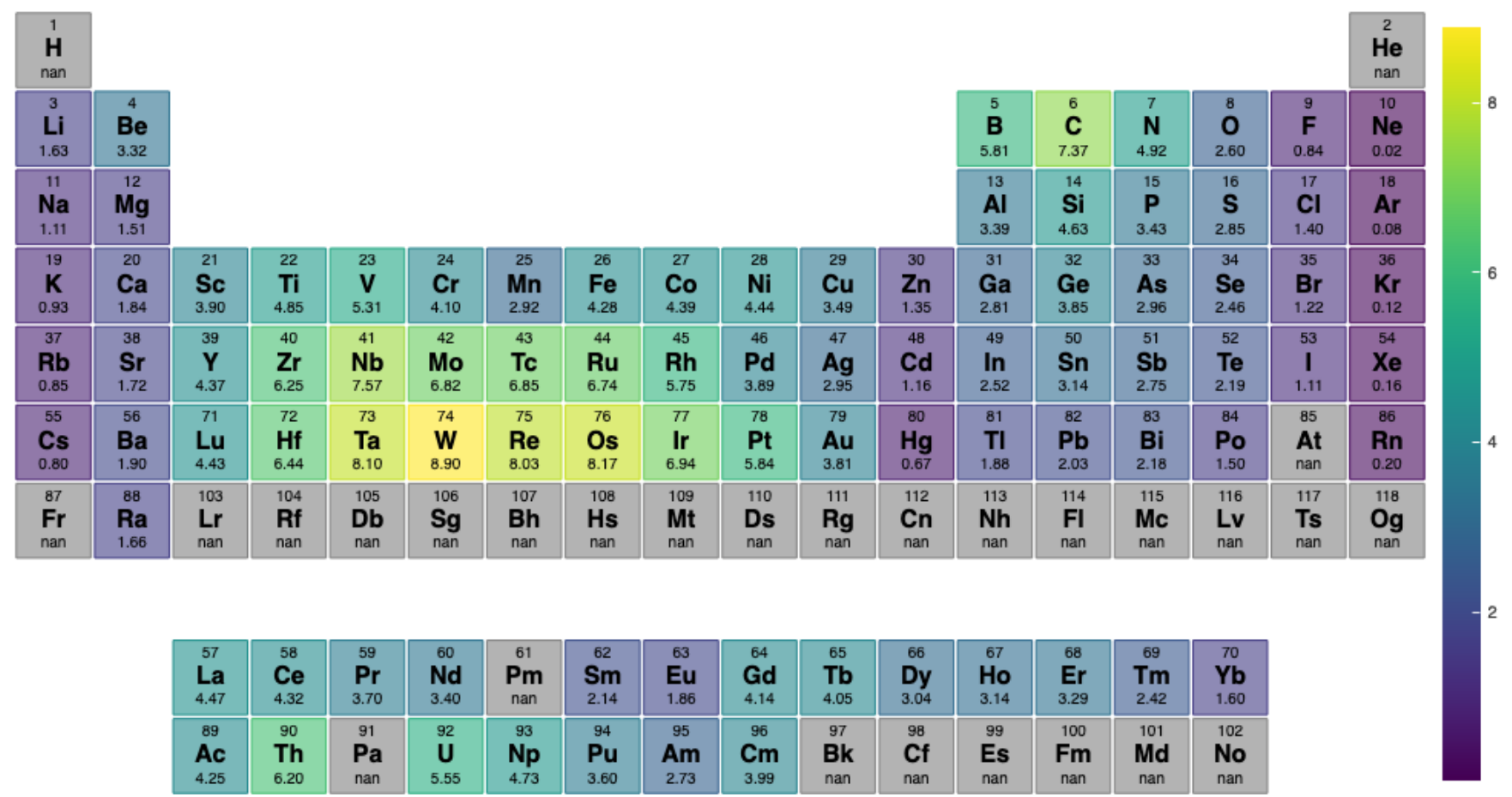

Figure S5. Periodic trends in experimental cohesive energies in eV/atom, ${ }^{3}$ listed below each element. We tabulated cohesive energies in element_cohesive_energies.csv. "nan" indicates unavailability of experimental cohesive energies (grey squares). 
(a) A-sites

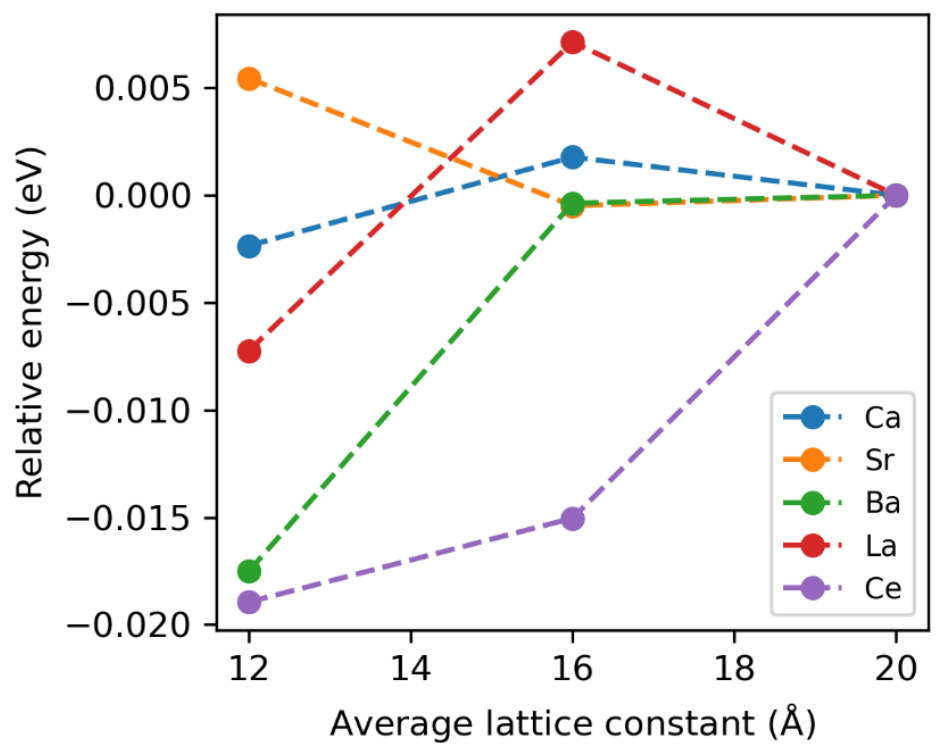

(b) B-sites

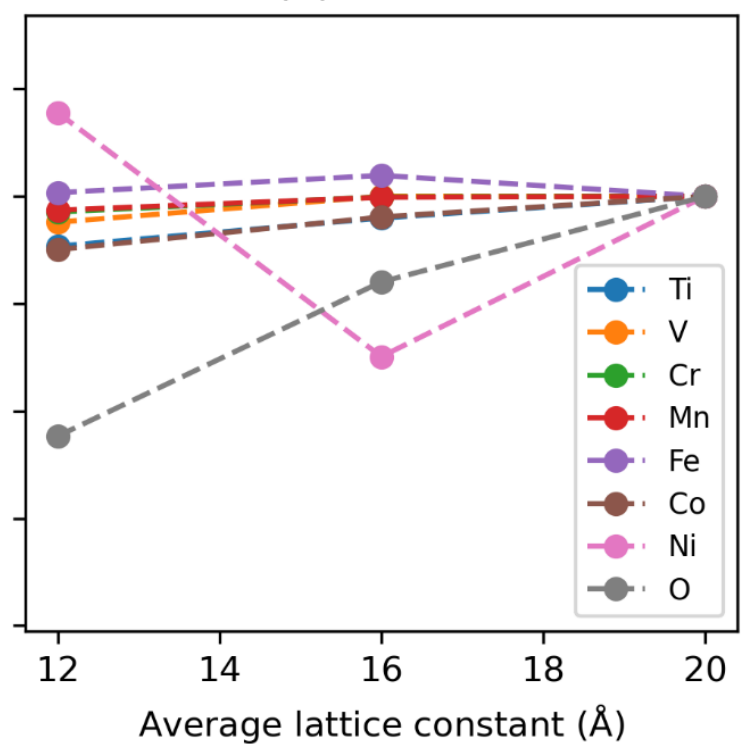

Figure S6. Cell-size convergence of total energies for neutral (a) A- and (b) B-site atoms in their electronic ground states. We tabulated atomic total energies in atoms.csv.
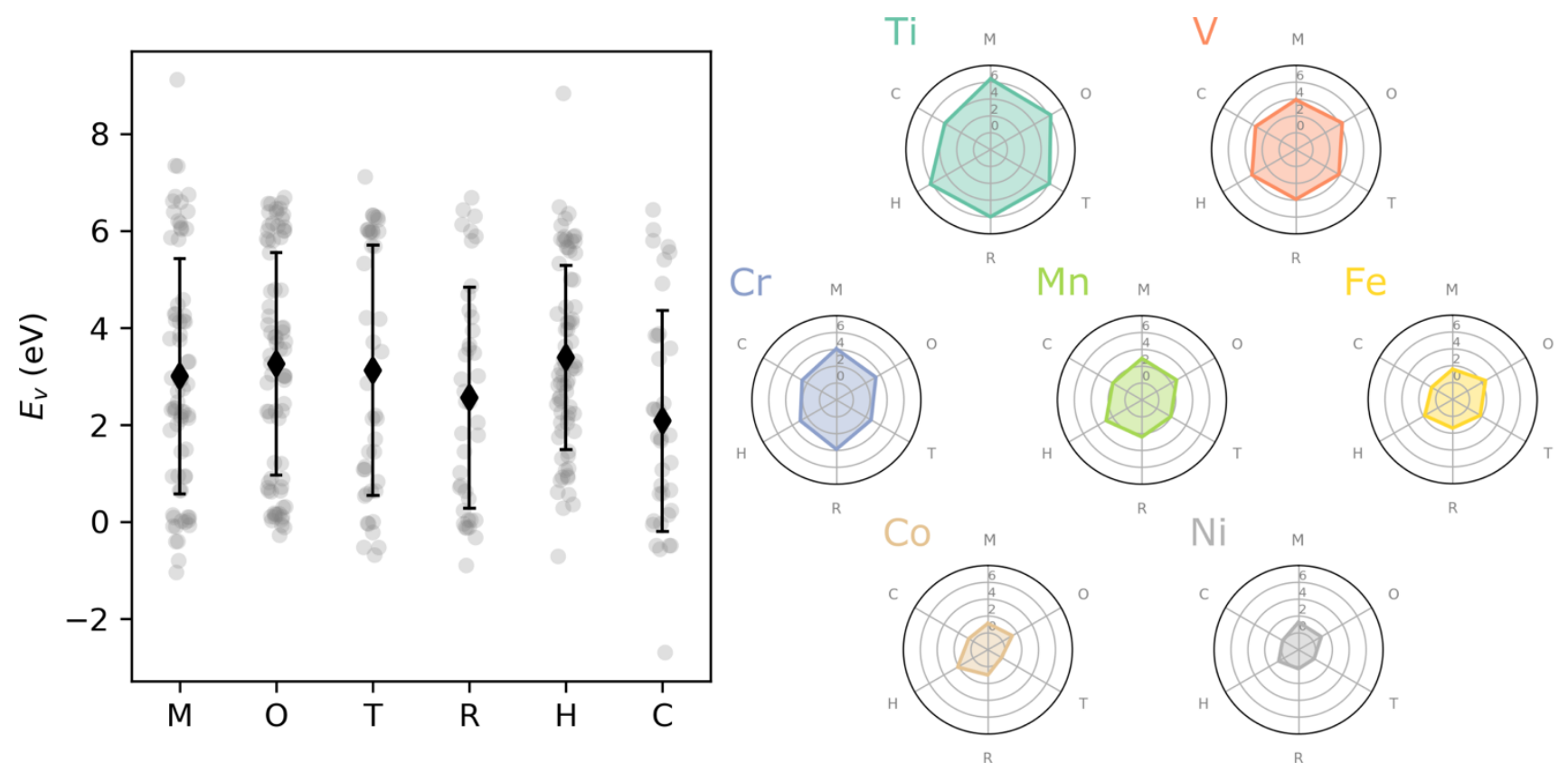

Figure S7. Effect of crystal system on $E_{v}$ where $M, O, T, R, H$, and $C$ are monoclinic, orthorhombic, tetragonal, rhombohedral, hexagonal, and cubic, respectively. Error bars show the standard deviation of $E_{v}$. All data are shown on the left whereas the data are collated by B-cation on the right (averages are shown as vertices along each crystal system axis). The left panel shows that no direct correlation exists between crystal system and $E_{v}$. On the other hand, Figure 6 in the main text shows a strong correlation between $E_{b}, V_{r}$, and $E_{v}$. Since Equations 2 and $\mathbf{5}$ in the main text indicate that $E_{b}$ and $V_{r}$ are structure independent while Equation 9 in the main text reveals that $V_{r}$ typically is that of the B-site cation, we 
also sorted by B-site cation (right panel) to uncover any further correlations. Still, only a weak, direct correlation is evident between crystal system and $E_{v}$ in the right panel (given by the degree of distortion away from a regular hexagon). Given that the two other descriptors in our model, $E_{g}$ and $E_{\text {hull, }}$ are indeed structure dependent, it appears that a weak, indirect correlation exists between crystal system and $E_{V}$ via $E_{g}$ and $E_{\text {hull. }}$

Table S2. Theoretical and experimental cohesive energies $\left(E_{c}\right)$ across all metal oxides considered.

\begin{tabular}{cccc}
\hline Metal oxide & SCAN+U $\boldsymbol{E}_{\boldsymbol{c}}(\mathbf{e V})$ & $\mathbf{E x p}^{3-6} \boldsymbol{E}_{c}(\mathbf{e V})$ & Relative error $(\mathbf{e V})$ \\
\hline $\mathrm{CaO}$ & 11.30 & 11.00 & 0.30 \\
$\mathrm{SrO}$ & 10.54 & 10.44 & 0.11 \\
$\mathrm{BaO}$ & 10.20 & 10.22 & -0.02 \\
$\mathrm{La}_{2} \mathrm{O}_{3}$ & 34.94 & 35.28 & -0.33 \\
$\mathrm{Ce}_{2} \mathrm{O}_{3}$ & 34.74 & 35.27 & -0.53 \\
$\mathrm{CeO}_{2}$ & 20.51 & 20.78 & -0.27 \\
$\mathrm{TiO}_{2}$ & 18.96 & 19.81 & -0.84 \\
$\mathrm{VO}_{2}$ & 17.41 & 17.87 & -0.46 \\
$\mathrm{CrO}_{2}$ & 15.68 & 15.30 & 0.38 \\
$\mathrm{MnO}_{2}$ & 13.52 & 13.48 & 0.05 \\
$\mathrm{FeO}_{2}$ & 12.75 & $\mathrm{n} / \mathrm{a}$ & $\mathrm{n} / \mathrm{a}$ \\
$\mathrm{CoO}_{2}$ & 12.07 & $\mathrm{n} / \mathrm{a}$ & $\mathrm{n} / \mathrm{a}$ \\
$\mathrm{NiO}_{2}$ & $\mathrm{n} / \mathrm{a}$ & $\mathrm{n} / \mathrm{a}$ \\
$\mathrm{Ti}_{2} \mathrm{O}_{3}$ & 11.76 & 33.21 & -1.75 \\
$\mathrm{~V}_{2} \mathrm{O}_{3}$ & 31.46 & 31.00 & -0.66 \\
$\mathrm{Cr}_{2} \mathrm{O}_{3}$ & 30.34 & 27.66 & 0.22 \\
$\mathrm{Mn}_{2} \mathrm{O}_{3}$ & 27.88 & 23.51 & 0.11 \\
$\mathrm{Fe}_{2} \mathrm{O}_{3}$ & 23.62 & 24.82 & -0.02 \\
$\mathrm{CO}_{3} \mathrm{O}_{4}$ & 24.80 & 32.88 & 0.23 \\
$\mathrm{Ni}_{2} \mathrm{O}_{3}$ & 33.12 & 21.70 & -0.02 \\
$\mathrm{CoO}^{\mathrm{NiO}}$ & 21.68 & 9.45 & 0.11 \\
& 9.56 & 9.52 & 0.05 \\
\hline
\end{tabular}


(a)

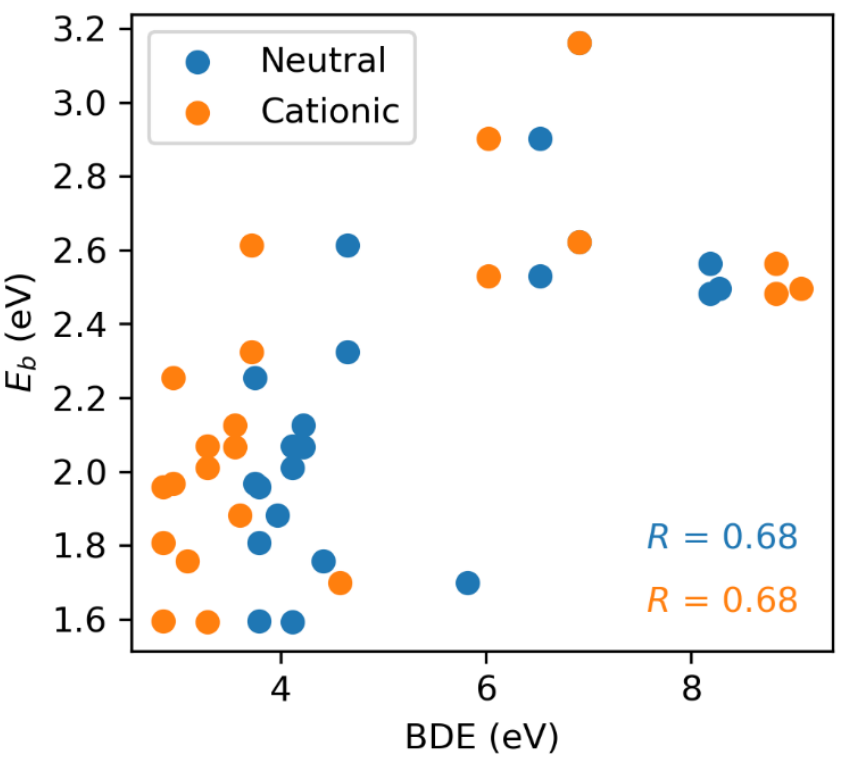

(b)

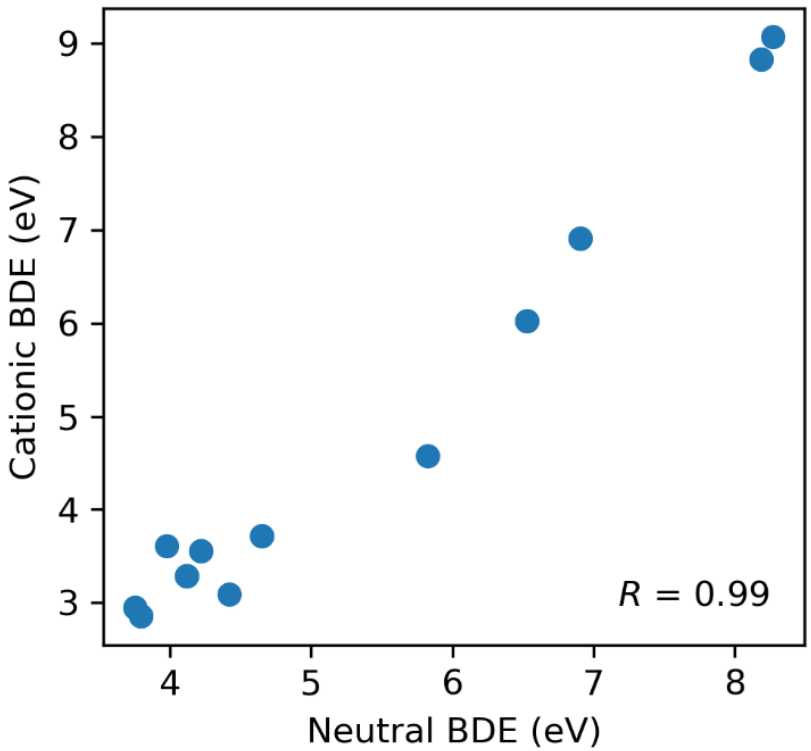

Figure S8. (a) Correlation of experimental bond dissociation energies (BDEs) for neutral diatomic molecules (blue) and diatomic cations (orange) with respect to SCAN+U-calculated crystal bond dissociation energies $\left(E_{b}\right)$ showing the difference between molecular and crystal bond strengths. $R$ is the Pearson correlation coefficient. ${ }^{7}$ (b) Experimental BDEs for neutral diatomic molecules strongly correlate with those of diatomic cations. We tabulated BDEs and $E_{b}$ in features.csv.

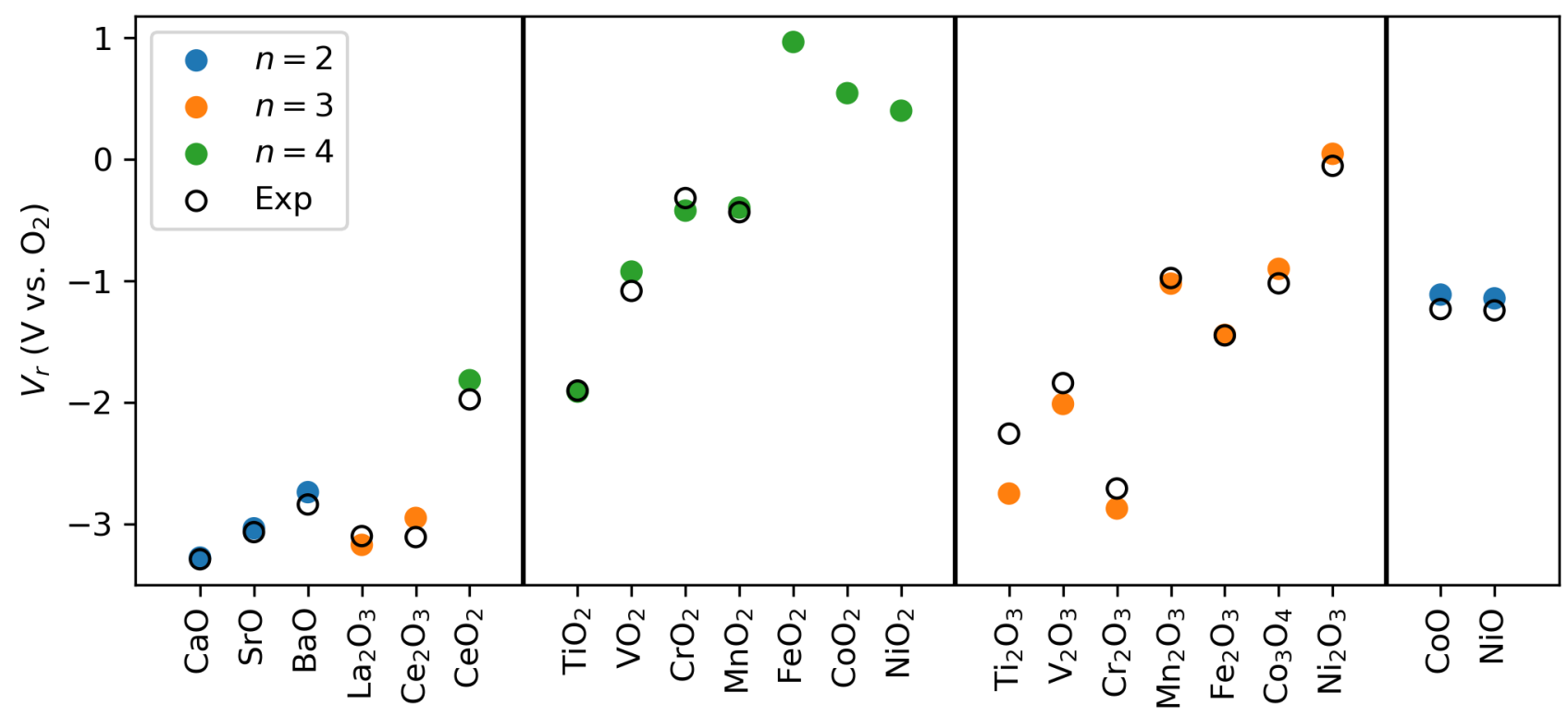

Figure S9. Specific trends in the SCAN+U-calculated and experimental $V_{r}$ vs. (a) A-site atoms $(+2 /+3 /+4)$, (b) B-site atoms with +4 oxidation state, (c) B with +3 , and (d) B with +2 . Experimental $V_{r}$ for $\mathrm{FeO}_{2}, \mathrm{CoO}_{2}$, and $\mathrm{NiO}_{2}$ are not available due to the metastability of binary $\mathrm{Fe}^{4+}, \mathrm{Co}^{4+}$, and $\mathrm{Ni}^{4+}$ oxides. We tabulated $V_{r}$ in features.csv. 

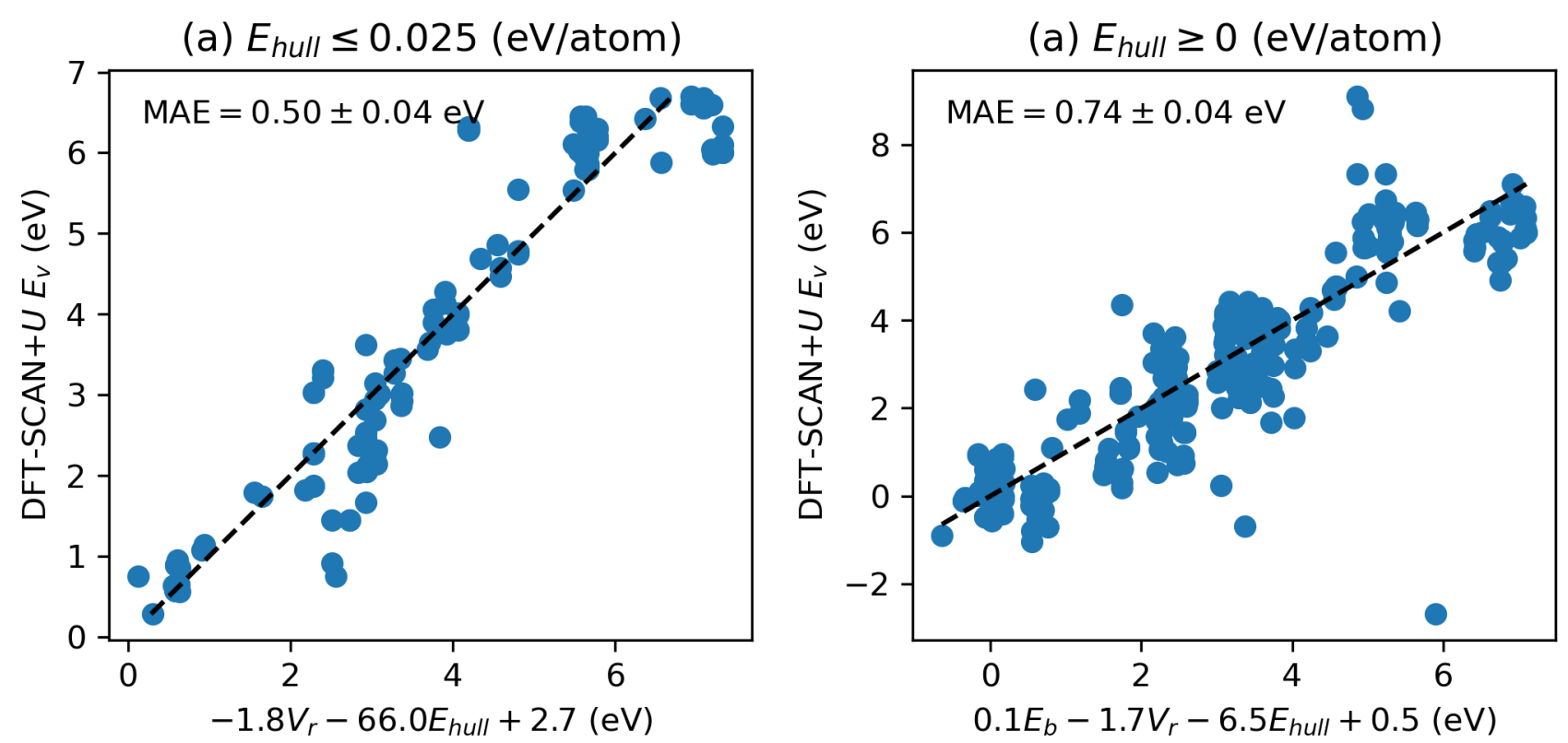

Figure S10. SCAN+U-calculated vs. simplified-model-predicted $E_{v}$ for (a) room-temperature-stable ( $E_{\text {hull }}$ $\leq 298.15 k_{B}$ ) and (b) all $\mathrm{ABO}_{3}$ perovskite structures considered.

\section{References}

(1) Wang, L.; Maxisch, T.; Ceder, G. Oxidation Energies of Transition Metal Oxides within the GGA+U Framework. Phys. Rev. B 2006, 73 (19), 195107. https://doi.org/10.1103/PhysRevB.73.195107.

(2) Sai Gautam, G.; Carter, E. A. Evaluating Transition Metal Oxides within DFT-SCAN and SCAN+U Frameworks for Solar Thermochemical Applications. Phys. Rev. Mater. 2018, 2 (9), 095401. https://doi.org/10.1103/PhysRevMaterials.2.095401.

(3) Kittel, C. Introduction to Solid State Physics, 8th ed.; McEuen, P., Ed.; Hoboken, NJ: J. Wiley, 2005.

(4) Kubaschewski, O.; Alcock, C. B. Metallurgical Thermochemistry, 5th ed.; Raynor, G. V., Ed.; Pergamon Press, 1959; Vol. 12. https://doi.org/10.1063/1.3060816.

(5) Wagman, D. D.; Evans, W. H.; Parker, V. B.; Schumm, R. H.; Halow, I.; Bailey, S. M.; Churney, K. L.; Nuttall, R. L. Erratum: The NBS Tables of Chemical Thermodynamic Properties. Selected Values for Inorganic and C1 and C2 Organic Substances in SI Units [J. Phys. Chem. Ref. Data 11, Suppl. 2 (1982)]; Lide, D. R., Ed.; American Chemical Society: Washington, DC, 1989; Vol. 18. https://doi.org/10.1063/1.555845.

(6) Barin, I. Thermochemical Data of Pure Substances; Wiley, 1995. https://doi.org/10.1002/9783527619825.

(7) Blyth, S. Karl Pearson and the Correlation Curve. Int. Stat. Rev. / Rev. Int. Stat. 1994, 62 (3), 393. https://doi.org/10.2307/1403769. 